\title{
ORIENTAÇÃO DO MOVIMENTO DO CORPO PELA EDUCAÇÃO DAS EXPRESSÕES: PERCEÇÕES DE PROFESSORES EM PORTUGAL
}

\author{
ORIENTATION OF BODY MOVEMENT THROUGH EDUCATION OF \\ EXPRESSIONS: PERCEPTIONS BY TEACHERS FROM PORTUGAL
}

\section{ORIENTACIÓN DEL MOVIMIENTO DEL CUERPO POR LA EDUCACIÓN DE LAS EXPRESIONES: PERCEPCIONES DE PROFESORES EN PORTUGAL}

\author{
André Freitas*, Ana Mouraz*, Fátima Pereira*
}

\section{Palavras chave:}

Docentes.

Ensino fundamental

e médio.

Movimento.

Educação Física.
Resumo: 0 desenvolvimento cognitivo, pessoal e social da criança é a finalidade que a educação básica em Portugal pretende atingir, a organizar curricularmente os saberes que permitirão às crianças experienciar diferentes cenários e conteúdos, estimulando suas aprendizagens. A educação das expressões artísticas e físico-motoras contribui de forma essencial para esse desenvolvimento integral. Assim, são reconfiguradas as dinâmicas pedagógicas, o que, consequentemente, especifica os movimentos do corpo de alunos. Os professores do ensino básico são, inevitavelmente, promotores dessas experiências. Este artigo apresenta um estudo que procurou identificar e caracterizar o modo como professores planejam e colocam em ação a educação artística e a Educação Física, desenvolvendo 0 conceito de educação das expressões, em que movimento é entendido como principal meio de comunicação das expressões. Recorreu-se a uma metodologia mista. Os resultados evidenciam uma estreita relação entre as condições organizacionais e os modos como os professores desenvolvem a criatividade e a motricidade das crianças.

\section{Keywords:}

Teachers.

Education, primary and secondary.

Movement.

Physical Education.

Abstract: School education in Portugal aims at students' cognitive, personal and social development by organizing the curriculum to include knowledge that enables children to experience different scenarios and contents and fostering students' learning. Teaching and learning of artistic and physical and motor expressions contributes to and is vital for students' development. Thus, pedagogical dynamics are reconfigured, which consequently specifies the movements of students' bodies. Teachers from basic education are undoubtedly the main promoters of such experiences. This paper finds and characterizes how teachers plan and implement Art Education and Physical Education by developing the concept of expressions' education in which movement is understood as the main means of communication. The study was developed through a mixed-method approach. The results reveal a close relationship between organizational conditions and how teachers develop students' creativity and motor skills.

Palabras clave: Docentes.

Enseñanza primaria y secundaria. Movimiento. Educación Física.
Resumen: El desarrollo cognitivo, personal y social del niño es el propósito de que la educación básica en Portugal pretende alcanzar al organizar curricularmente los saberes que permitirán a los niños experimentar diferentes escenarios y contenidos, estimulando sus aprendizajes. La educación de las expresiones artísticas y físico-motoras contribuye de forma esencial con este desarrollo integral. Así, son reconfiguradas las dinámicas pedagógicas, lo que, consecuentemente, especifica los movimientos del cuerpo de los alumnos. Los maestros de la enseñanza primaria son, inevitablemente, los promotores de estas experiencias. Este artículo presenta un estudio que buscó identificar y caracterizar el modo en que los profesores planean y ponen en acción la Educación Artística y la Educación Física, desarrollando el concepto de educación de las expresiones, donde el movimiento es entendido como el principal medio de comunicación de las expresiones. Se ha recurrido a una metodología mixta. Los resultados muestran una estrecha relación entre las condiciones de organización y las formas en que los maestros desarrollan la creatividad y la motricidad de los niños.
*Universidade do Porto. Porto, Portugal. E-mail: andrefsantos27@gmail.com; anamouraz@fpce.up.pt

Recebido em: 02-11-2016 Aprovado em: 10-11-2017

DOI: http://dx.doi.org/10.22456/1982-8918.69218 (c) (1) (8) Licence 


\section{INTRODUÇÃOO}

As atividades de expressão das crianças realizam-se pelas suas manifestações corporais, vocais, dramáticas, grafo-plásticas, entre outras (SANTOS, 1999), em processos experimentais que as acompanham desde que nascem (SOUSA, 2003a). São estas valências, naturais na vida da criança, que, quando orientadas, potenciam o seu desenvolvimento pessoal, cognitivo e social. É essa necessidade de orientação que justifica o conceito de Educação das Expressões.

As singularidades constituintes da expressão permitem que as peculiaridades das crianças, tais como o instinto, as emoções e os sentimentos, sejam alcançadas e reconhecidas pelos adultos - os professores no ensino das expressões - através da sua transposição para formas e materiais (EISNER, 1972; SOUSA, 2003a). Assim, todas as crianças, pedagogicamente orientadas ou não, realizam atos expressivos; contudo, para que seja possível descobrirem as potencialidades da sua expressão como canal para a transmissão dos seus sentimentos e emoções, é necessário que o sistema educativo, onde estas se encontram, as trabalhe pedagogicamente, conferindo-lhes sentidos educativos. Tal é possível a partir da relação pedagógica que os professores estabelecem com alunos, considerada como primeira fonte de identidade profissional (PEREIRA; MOURAZ, 2015).

O alcance da expressividade das crianças nas escolas é permitido pelas atividades educativas organizadas e dinamizadas pelos professores, que cumprem dois tipos de objetivos: os instrutivos e os expressivos (EISNER, 1972). Os objetivos instrutivos ou de instrução dizem respeito, segundo Eisner (1972), à necessária aquisição de competências pelo meio da experimentação, importando o manuseamento de materiais, em vez da construção performativa de alto desempenho. 0 manuseamento de materiais significa a transposição dos objetivos para noções de materialidade (BARRETT, 1979), entendendo-se materialidade como todas as formas possíveis de manifestação, quer seja associada ao corpo como forma final, quer seja impregnada numa forma externa. Por ser "[...] através da manipulação daquilo que nos rodeia que conseguimos controlar o meio ambiente para fins pessoais ou sociais" (BARRETT, 1979, p.18, tradução nossa), assim que as crianças reconhecem as potencialidades do "material", torna-se possível a sua transposição para objetivos expressivos. É com base em Eisner (1972) que Barrett (1979, p.47, tradução nossa) explicita o que são objetivos expressivos: "Um objetivo expressivo é, para o professor e para o aluno, o convite à exploração [que] parte de assuntos, ou põe-nos em foco, que são de interesse especial ou importantes para quem os vai explorar. Um objetivo expressivo é mais evocativo do que prescritivo". Estes objetivos deverão ser promovidos no trabalho do professor, que, segundo Eisner (1972), e acreditando nos sonhos, nos desejos e nas intenções que preenchem a vida das crianças, é possível a partir das suas emoções e sensações desenvolver-se a expressão. Assim, a expressão ocorre quando o "material" se torna resultado transformado pela criança, compreendendo em si as emoções e sentimentos (EISNER, 1972; BARRETT, 1979).

Em virtude deste percurso de criação da expressão, em torno de processos emotivos e sentimentais, não é de estranhar que a atividade levante suspeitas (ARNHEIM, 1993). Read (1943) já nos falava da dificuldade de definição de arte, por esta ter vindo a ser estudada e trabalhada como um conceito metafísico, quando na verdade a arte é fundamentalmente um fenómeno orgânico, intrínseco às crianças e aos adultos (BARRETT, 1979). Arte que se 
expressa pela pintura ou escultura, assim como pela dança ou a ginástica. Frequentemente são os professores que não compreendem este conceito, e as repercussões acontecem no trabalho pedagógico que desenvolvem (SOUSA, 2003). A dinamização de atividades educativas que só abordam o primeiro momento da criação da expressão, com objetivos instrumentais ou instrutivos, verifica-se, por exemplo, quando pintar se torna um exercício em que os professores recorrem a imagens já existentes, sem a participação dos alunos (BARRETT, 1979), ou quando a música que é tocada na aula de dança não faz parte dos interesses dos alunos; ora porque se "[...] ensina música pela pauta, sem antes a criança ter tido quaisquer experiências no mundo dos sons" (SOUSA, 2003, p.81), ora porque os alunos não tiveram um primeiro contacto com os possíveis movimentos do corpo, antes de aprender uma coreografia. Deste modo, são desenvolvidos exercícios que possibilitam a aquisição de competências sem sentido (EISNER, 1972; BARRET, 1979). Está-se perante um ato que restringe o que deverá ser a Educação das Expressões. "Tal insensibilidade para com as crianças reduz a arte [e os processos criativos] a um espaço mecânico, sem vida e sem sentido, quer para professores, quer para alunos" (EISNER, 1972, p.157, tradução nossa), contrariando-se o que se espera ganhar quando as expressões são incluídas na educação, na sua verdadeira essência: pronunciar a vida da criança (cf. ARNHEIM, 1993).

Assim, a importância de se investigar a educação da expressividade na escola é de interesse fundamental para a vida das crianças e o seu desenvolvimento.

\section{A EDUCAÇÃO DAS EXPRESSÕES NO ENSINO BÁSICO COMO SABER GLOBALIZANTE}

As atividades educativas das expressões desenvolvidas como áreas programáticas do currículo situam-se em ilhas sem um mar que as una. O propósito da educação escolar deveria ser a transdisciplinaridade de conhecimentos e a exploração de sentidos sem barreiras. Todavia, não o sendo porque a organização curricularmente vigente assim as designa em conjunto, o propósito da Educação das Expressões (e será esta a nossa defesa nos próximos parágrafos) deveria assegurar, pelo menos, a existência de uma ponte entre o que apelidam de expressão artística e o que designam de expressão físico-motora. Segundo Read (1943), as expressões devem ser vistas e trabalhadas como um saber globalizante que compreenda a sua capacidade de reconfiguração das estruturas físicas e psicológicas da criança, ao invés de adotar funções instrumentalistas. Essas atividades, enquadradas num conjunto de objetivos pedagógicos, designado por currículo prescrito (PACHECO, 1996), traduzem-se, na perspetiva de Eisner (1972), em oportunidades de experiência, de forma sequencial, corporizando o currículo vivido (PACHECO, 1996). Neste sentido, as variações e as possibilidades de expressão a serem trabalhadas no currículo são imensas, uma vez que as atividades podem basear-se em conceitos de emoção, como a dor ou a alegria (SANTOS, 1989).

O programa curricular das expressões artísticas e físico-motoras no $1^{0}$ ciclo do ensino básico (CEB) em Portugal ${ }^{1}$ compreende quatro áreas de expressão: a expressão plástica; a expressão musical; a expressão dramática; e a expressão físico-motora. No entanto, face ao antes argumentado sobre a necessária articulação entre as diferentes expressões, desenvolverse-á o conceito de Educação das Expressões. 


\section{IDENTIFICAÇÃO E CARACTERIZAÇÃO DOS PRINCÍPIOS PEDAGÓGICOS DAS EXPRESSÕES}

A expressão e educação físico-motora é consagrada nas orientações curriculares do $1^{\circ}$ CEB (decreto-lei n.ำ 209/2002). É aí apresentada como o conjunto das atividades promotoras do desenvolvimento físico da criança. São objetivos do 1ํ CEB o "[...] desenvolvimento da linguagem oral e a iniciação e progressivo domínio da leitura e da escrita, das noções essenciais da aritmética e do cálculo, do meio físico e social, das expressões plástica, dramática, musical e motora" (art. 8o ponto 3 do Decreto-lei $n^{\circ} 46 / 86$ de 14 de outubro). As atividades incluídas nessa forma de expressão permitem o desenvolvimento de competências motoras e relacionais, uma vez que o uso do corpo e do movimento, segundo Condessa (2008), possibilita às crianças que conheçam a sua corporalidade, desenvolvam a sua autonomia e interajam com os grupos, no quadro das diferentes estruturas organizacionais em que se inserem. A exploração do movimento é a argumentação que fundamenta o princípio pedagógico orientador da expressão físico-motora que inclui a dança como uma dimensão importante. Mais do que ensinar a dançar, deve-se ensinar a explorar o movimento permitido pela dança, traduzindo-se numa "iniciação à aprendizagem das suas técnicas específicas" (SOUSA, 2003a, p.201).

Apesar disso, ainda é visível na escola do 1ํ CEB o constrangimento das expressões, quer pela imposição de espaços reduzidos, em virtude das condições e características das escolas do $1^{\circ}$ CEB, sem atenção ao desenvolvimento da criança, o que origina expressões quotidianas que se ouvem nas escolas "Não vás para aí!, Está quieto!, Está calado" (SOUSA, 2003a, p.123). É na articulação entre os princípios pedagógicos das expressões e as características da turma que o professor deve possibilitar a construção de "oportunidades para que as crianças realizem experiências na área da atividade física em atividades que sejam estimulantes, diversificadas e integradoras" (CONDESSA, 2008, p.350).

As dimensões que compõem a amplitude das capacidades expressivas das crianças são infinitas, na medida em que a sua criação e sua manifestação são constantemente alteradas, em virtude do seu estado social e cognitivo estar em desenvolvimento. Segundo os princípios orientadores do Ministério da Educação (ME), através do manual de organização curricular e programas do $1^{\circ}$ ciclo para a expressão e educação musical, é "através do corpo em movimento, de uma forma espontânea ou nos jogos de roda e nas danças - formas mais organizadas do movimento - [que] as crianças desenvolvem potencialidades musicais múltiplas" (PORTUGAL, 2004, p.67), como a alegria, traduzindo-se no riso, a fúria e libertação de tensões, desencadeando o choro ou invenção de ritmos com o seu corpo.

Os princípios naturais na vida de uma criança poderão ser valorizados pedagogicamente, na medida em que a expressão musical possibilita, por exemplo, o ritmo, ou seja, a plasticidade do movimento (SANTOS, 1989), quer seja alcançada com instrumentos sonoros com propriedades como as madeiras, as cordas, ou as peles, quer seja no corpo das crianças. Estes instrumentos são um complemento da ação musical das crianças, uma vez que mais do que aprender música é importante que as crianças se familiarizem com os sons da descoberta, da invenção e da criação, pois o objetivo da educação pela música é a criança e não a música. Em exercícios de corrida, salto ou jogo tático com colegas de turma, o som é constante, podendose tirar partido das potencialidades musicais durante os seus movimentos.

A integração criativa e harmoniosa da voz, do corpo e dos instrumentos é, segundo 0 Manual de organização curricular e programas do $1^{\circ}$ ciclo (2004), a "receita" para atender à 
importância da exploração do mundo sonoro, em que o objetivo da expressão é a satisfação das necessidades da criança e o desenvolvimento das suas capacidades, como a perceção, a atenção, a memória (SOUSA, 2003b). Os professores e a estrutura organizacional do $1^{0}$ CEB devem, portanto, interessar-se pelo desenvolvimento equilibrado das crianças, em vez de prepará-las para um mundo performativo, para serem músicos, ginastas ou bailarinos.

Relativamente à expressão plástica, este termo surge, segundo Sousa (2003b), adotado pelo movimento da educação pela arte em Portugal para designar "o modo de expressãocriação através do manuseamento e modificação de materiais plásticos" (p. 159). É, uma vez mais, a experimentação do material que permitirá à criança atribuir significados próprios ao manuseamento do barro, das tintas aguadas e dos pincéis. A expressão nas artes plásticas deve ser a permissão e o incentivo para que a criança crie e desenvolva, ao invés de ser um pretexto que pressupõe um resultado de reprovação. Desta forma, espera-se que o resultado, enquanto como único momento de avaliação (qualquer que ela seja), é insuficiente para a compreensão da criança no processo educativo (PACHECO, 2002). Segundo Sousa (2003b), 0 adulto geralmente aprecia o trabalho da criança enquanto resultado, e não o processo que engloba o conteúdo emocional-sentimental. Ora, "[...] a criança, quando desenha ou pinta, não o faz com a intenção de criar qualquer obra para ser contemplada ou avaliada por outros" (SOUSA, 2003b, p.167), importando então que a criança faça, ao invés da avaliação e da atenção do professor estar no que faz e como faz. Em suma, o pressuposto da avaliação deve centrar-se na relação e na comunicação estabelecida entre professor e aluno (PACHECO, 2002), revelando intersubjetividades face aos critérios definidos.

É na relação entre os conteúdos do mundo que envolvem as crianças, tais como o oceano, as ilhas, o céu e os animais, assim como a liberdade de tema, com espaço para a espontaneidade, que o professor deve organizar o seu trabalho pedagógico (BARBOSA, 2005). No pressuposto de o trabalho do professor já permitir a espontaneidade (SOUSA, 2003a, com base em GONÇALVES, 1991), esta é um elemento do processo de expressão das crianças. Desta forma, a educação permite que a criança não viva num ambiente obediente, passivo e submisso, mas sim numa atmosfera de permissão da experiência, da criação, da criatividade e da liberdade.

O corpo, apresentado até agora como principal proporcionador da atividade expressiva, encontra na expressão e educação dramática mais uma oportunidade de explorar "situações imaginárias, a partir de temas sugeridos pelos alunos ou propostos pelo professor, [dando] [...] oportunidade a que a criança, pela vivência de diferentes papéis, se reconheça melhor e entenda melhor o outro" (PORTUGAL, 2004, p.77). A Educação Física revela-se intrínseca em todas as formas de expressão, pois é o corpo que se torna meio e fim, no seu controle e exploração de movimentos, coreografados ou espontâneos.

A educação pela expressão dramática possibilita a abstração do mundo real, onde, de forma espontânea, a criança pode embalar uma boneca e fingir que é mãe ou abrir os braços e ser um avião (SOUSA, 2003a). Estas manifestações não são representações teatrais, mas sim uma ação lúdica, "[...] apenas pelo prazer que isso lhe dá, pela satisfação em expressar por este modo as suas emoções, pelos sentimentos de alegria e de felicidade que sente na realização deste ato em si" (SOUSA, 2003a, p.22). A expressão dramática é um "[...] modo globalizador próprio da criança, onde os gestos, a voz, o movimento, as atitudes, e todos os meios expressivos que possui, revelam o seu mundo interior" (SANTOS, 1999, p.71). 
Esta manifestação, aliada aos saberes do professor, com propriedades próprias de trabalho pedagógico, vai para além da movimentação muscular do corpo. A expressão dramática é desinibidora das movimentações, é geradora de autoconfiança, é resolutória de problemas inter e intrapessoais (TORMENTA, 2015) e, aliada à presença de uma coordenação pedagógica, permite que estas manifestações, que poderão ser de carácter mais onírico (MALPIQUE; LEITE, 1986) ou performativo (TORMENTA, 2015), expressando uma característica ou bem físico, sejam reconhecidas como capacidades de comunicação em vários suportes.

A multidisciplinaridade e a transversalidade das diferentes áreas de expressão devem ser a atitude a adotar, uma vez que o corpo é o "órgão" catalisador das manifestações expressivas das crianças. $O$ corpo em movimento é o mesmo em todas as atividades desenvolvidas, porém é a especificidade de cada expressão que contribui para o desenvolvimento da criança. A educação das expressões é a construção pedagógica de oportunidades para as crianças se comunicarem com quem as rodeia; uma oportunidade para que as crianças conheçam a sua comunidade; se conheçam a si mesmas; cresçam e se desenvolvam.

\section{METODOLOGIA}

Este estudo recorre a uma metodologia mista (CRESWELL, 2003) que combina dados quantitativos e dados qualitativos. A estrutura da pesquisa segue uma utilização sequencial destas abordagens, inicialmente com recolha de informação predeterminada e, posteriormente, com a possibilidade de se apresentarem assuntos emergentes numa segunda recolha de dados acerca das atividades educativas dinamizadas. Tal permite responder-se ao objetivo deste artigo, que é identificar e caracterizar o modo como os professores planeiam e colocam em ação a educação artística e a Educação Física.

Inicia-se a recolha de informação por método quantitativo, analisando-se os dados estatisticamente, permitindo, posteriormente, a partir dos resultados encontrados, elaborar uma proposta de aprofundamento de conhecimento do tema, por meio de recolha de informação de cariz qualitativo. Os resultados encontrados na segunda recolha de informação permitiram fazer uma interpretação mais sustentada.

Os dados de cariz quantitativo foram recolhidos através de um questionário semiestruturado e os dados qualitativos foram obtidos mediante a realização de entrevistas. Acerca dos questionários, importa referir que se recorreu a propriedades de escala métrica ordinal, por via de uma escala de Likert de 7 pontos. A escolha de uma escala de 7 pontos visou aumentar a amplitude das respostas, possibilitando, de igual forma, uma maior variação. A escala de Likert, de caráter ordinal, regular e com um intervalo equitativo, faz com que seja "[...] frequentemente utilizada em questões de opinião e atitudes" (COHEN; MANION; MORRISON, 2007, p.502). A escala adotada no questionário foi utilizada para assinalar-se concepções com grau de importância, de "nada importante" (1) a "imprescindível" (7), assim como para se assinalar graus de concordância, de "discordo totalmente" (1) a "concordo totalmente" (7).

Quanto às entrevistas, importa referir que se abordaram, num primeiro momento, a legitimação do encontro e a motivação dos presentes, a que se seguiu uma breve caracterização da formação e percurso profissional dos participantes. As restantes dimensões foram os contextos de trabalho, a organização curricular posta em prática pelos professores e o trabalho 
desenvolvido na componente da educação das expressões. A análise de conteúdo realizou-se de acordo com o estabelecido por Bardin (2011).

Os sujeitos participantes são 101, contando-se com 96 professores do $1^{\circ} \mathrm{CEB}$, na primeira recolha de dados, e com outros dois momentos de recolha de dados, um por entrevista a um professor com funções de gestão pedagógica e administrativa e um outro momento de grupo focal com um grupo de professoras do $1^{\circ}$ CEB de um Agrupamento de escolas.

\section{RESULTADOS}

As tendências dominantes do trabalho curricular, percebidas pelos professores respondentes, concorda moderadamente com a importância das competências de literacias básicas e a menor ênfase no trabalho da educação das expressões. Os docentes concordam ( $\chi$ : média das respostas $=5,10$; dp: desvio padrão das respostas $=1,88$ ) acerca de as tendências dominantes da organização curricular do 1ํ CEB centrar-se em na uniformização do saber ler, escrever e contar. Os docentes concordam $(\chi=5,48 ; d p=1,550)$ acerca de a excessiva formalização e o controlo das tarefas docentes lesarem o trabalho curricular da educação das expressões.

A formalização e burocratização do sistema foram referidas nos discursos das professoras. A professora Marta faz notar que a importância atribuída à matemática e ao português, no trabalho pedagógico dos professores, impossibilita que tenham tempo para trabalhar curricularmente a educação das expressões: "Nos últimos anos, o enfoque tem sido dado à matemática e ao português e as expressões acabam um bocadinho por ser o parente pobre no trabalho que nós estamos vindo a efetuar" (Marta).

Acerca da importância dos recursos materiais, tanto na troca entre professores como na existência, no que diz respeito ao desenvolvimento das expressões, os professores discordam pouco $(\chi=3,59 ; \mathrm{dp}=1,83)$ da sua existência nas escolas. Quanto à existência dos recursos físicos e materiais como condições para o exercício profissional na organização curricular da educação das expressões, os professores discordam pouco $(\chi=3,72$; $d p=1,85)$ da escola dispor de recursos materiais adequados ao trabalho das expressões: "Materiais, está fora de questão. São das senhoras professoras que trazem de casa, porque são umas queridas. Não temos sequer espaços físicos" (Sofia).

Os espaços onde decorrem, maioritariamente, as atividades de expressão que são dinamizadas pelos professores são as salas de aula. Especificando, os espaços onde decorrem maioritariamente as atividades de expressão e educação físico-motora são no recreio, de acordo com 63 professores $(65,6 \%)$. As restantes áreas maioritariamente utilizadas são 0 ginásio, segundo 23 professores (24\%), a sala de aula, de acordo com sete professores $(7,4 \%)$, e um professor responde que não são dinamizadas atividades de expressão e educação físicomotora. Registraram-se, ainda, duas respostas $(2,1 \%)$ omissas. Não se registraram respostas sobre a possibilidade de serem dinamizadas atividades em locais externos à escola. O local onde decorrem, maioritariamente, as atividades de expressão e educação musical são a sala de aula, o que é reconhecido pelas respostas de 91 professores (94,8\%); dois professores $(2,1 \%)$ não dinamizam atividades e um professor (1\%) dinamiza no ginásio. Registraramse, ainda, duas respostas $(2,1 \%)$ omissas. O local onde decorrem, maioritariamente, as atividades de expressão e educação dramática são a sala de aula, o que é reconhecido por 87 
professores $(90,6 \%)$; dois professores $(2,1 \%)$ não as dinamizam e um professor $(1 \%)$ dinamiza as atividades no ginásio. Registraram-se, ainda, seis respostas (6,3\%) omissas. O local onde decorrem maioritariamente as atividades de expressão e educação plástica é a sala de aula, o que é reconhecido por 93 professores (96,9\%). Registraram-se, ainda, três respostas $(3,1 \%)$ omissas.

\subsection{Trabalho curricular em educação das expressões no ensino básico: planejamento de atividades}

Os professores concordam $(\chi=5,07 ; d p=1,53)$ que a planificação das atividades depende dos objetivos preconizados pelo Ministério da Educação, assim como concordam ( $\square$ $=4,95 ; \mathrm{dp}=1,71$ ) que as expressões são uma área disciplinarizada, como a matemática ou 0 estudo do meio.

Os professores discordam bastante $(\chi=2,15$; $d p=1,48)$ sobre 0 planejamento das atividades na área das expressões ser realizado em conjunto com o departamento das expressões ${ }^{2}$, e da afirmação de $(\chi=2,03 ; \mathrm{dp}=1,25)$ que o planejamento das atividades na área das expressões deve ser mais rigoroso e cuidado do que as restantes áreas.

A segunda recolha de informação permitiu, sobretudo, aprofundar de que modo são planejadas as atividades de educação das expressões e quais os seus efeitos na educação das crianças.

Os planejamentos das atividades de educação das expressões são cumpridores das orientações do $\mathrm{ME}$, recorrendo-se à partilha de fichas de planificação e à conversa entre professores, nas escolas, para a sua concretização. Apesar dos esforços, as professoras argumentam que as diretrizes para 0 1 CEB são incongruentes com as orientações de cada área programática.

\subsection{Trabalho curricular da educação das expressões no ensino básico: dinamização de atividades}

Os professores concordam ( $\chi=4,84 ; d p=1,60)$, apesar da pequena margem que existe com os que discordam, que no currículo do 1을 CEB existe a oportunidade efetiva de se desenvolver a expressão pessoal (artística e físico-motora) das crianças, ao passo que discordam $(\chi=3,89 ; \mathrm{dp}=1,98)$ da ideia de as Atividades de Enriquecimento Curriculares (AEC) substituírem, frequentemente, o desenvolvimento curricular das expressões. No entanto, é de salientar o valor elevado da dispersão das respostas, neste item. As Atividades de Enriquecimento Curricular (AEC), de frequência facultativa, surgem segundo a operacionalização do programa Escola a Tempo Inteiro (ETI). São atividades dinamizadas por técnicos especializados e contratados pelo agrupamento de escolas.

Apesar de os professores dizerem que as AEC não substituem o trabalho curricular na educação das expressões ( $\chi=3,89 ; \mathrm{dp}=1,98)$, encontrou-se uma diferença estatisticamente significativa entre as respostas dos docentes que têm funções de gestão e de supervisão pedagógica e as dos que as não têm. Os primeiros concordam mais com o item $(p=0,020)$. 
Os professores discordam ( $\chi=3,67 ; d p=1,73$ ) da coadjuvação não ser sistemática, mas sim variar em função da atividade de expressão em dinamização. Os professores concordam $(\chi=5,56 ; \mathrm{dp}=1,33)$ que as atividades de expressão servem, frequentemente, de motivação dos alunos para outras áreas curriculares.

Os resultados encontrados na análise das entrevistas acerca da dinamização das expressões ser maioritariamente entregue às AEC contraria os resultados da análise das respostas dos professores inquiridos por questionário. As professoras argumentam que as atividades da educação das expressões não decorrem do trabalho que desenvolvem com as crianças, em tempo lectivo.

Quanto ao recurso das expressões artísticas e físico-motoras para servir frequentemente de motivação dos alunos para outras áreas curriculares, as professoras inquiridas identificam e aprofundam esta ideia:

Era a partir das expressões que se devia ensinar tudo o resto. E se começássemos a agarrar as expressões, que os miúdos podem desenvolver, as outras [áreas] vinham por acréscimo (Marta).

As expressões deviam passar [pelo nosso trabalho] porque é assim que os temos na mão e é assim que podemos trabalhar conteúdos complicados de uma forma engraçada, de uma forma em que eles veem, em que eles sentem e em que eles tocam (Sofia).

Na primeira recolha de informação, por questionário, os professores foram inquiridos acerca de que tipo de atividades de expressão artística e físico-motora desenvolveram com a sua turma, na última semana, a partir de uma lista de atividades selecionadas das orientações do ME (PORTUGAL, 2004). Foi possível a construção de uma tabela organizadora.

Tabela 1 - Atividades de expressão artística e físico-motoras trabalhadas na última semana.

\begin{tabular}{lcccc}
\hline \multicolumn{1}{c}{ Atividade } & Sim & Percentagem & Não & Percentagem \\
\hline Subir e descer o espaldar & 4 & 4,2 & 92 & 95,8 \\
Cantar canções & 86 & 89,6 & 10 & 10,4 \\
Fazer e desmanchar construções & 23 & 24 & 73 & 76 \\
Inventar e utilizar máscaras & 21 & 21,9 & 75 & 78,1 \\
Rodar o arco à volta do corpo & 18 & 18,8 & 78 & 81,3 \\
Desenhar no chão do recreio & 11 & 11,5 & 85 & 88,5 \\
Participar em danças de roda, de fila,... & 34 & 35,4 & 62 & 64,6 \\
Improvisar sons e atitudes em interação & 54 & 56,3 & 42 & 43,8 \\
Recitar textos & 71 & 74 & 25 & 26 \\
Driblar com cada uma das mãos & 16 & 16,7 & 80 & 83,3 \\
Reconhecer ritmos da vida & 25 & 26 & 71 & 74 \\
Modelar usando utensílios & 22 & 22,9 & 74 & 77,1 \\
Saltar ao eixo & 7 & 7,3 & 89 & 92,7 \\
Construir instrumentos musicais & 4 & 4,2 & 92 & 95,8 \\
Pintar livremente em grupo sobre grandes dimensões & 40 & 41,7 & 56 & 58,3 \\
Elaboração oral de uma história & 61 & 63,5 & 35 & 36,5 \\
\hline
\end{tabular}

Fonte: Elaborada pelos autores (dados da pesquisa). 
As atividades maioritariamente desenvolvidas são "cantar canções", "improvisar sons e atitudes", "recitar textos" e "elaboração oral de uma história", enquadradas nas atividades destinadas à expressão e educação dramática e musical. Essas atividades têm como blocos organizativos as áreas da linguagem verbal e linguagem gestual. Os resultados demonstram, ainda, que as restantes atividades no quadro não foram desenvolvidas.

Os professores identificam, como primeira opção, a existência de recursos físicos e materiais $(25,4 \%)$ como facilitador do trabalho curricular das atividades de expressão artística e físico-motora. Os outros dois aspetos que facilitam o trabalho curricular das expressões artísticas e físico-motoras, maioritariamente identificados pelos respondentes, são a motivação demonstrada pelos alunos (16,9\%) na realização das atividades, assim como a transdisciplinaridade entre conteúdos (15,2\%) permitida pelas expressões artísticas e físico-motoras.

Quanto aos resultados acerca dos fatores que fragilizam e prejudicam a dinamização de atividades da educação das expressões, são eles: os recursos físicos e materiais para cerca de metade dos respondentes. Os outros dois principais aspetos que fragilizam o trabalho curricular nas expressões, identificados pelos respondentes, são a extensão do currículo e do programa (15\%) e a subvalorização das expressões artísticas e físico-motoras (13,3\%), quer seja pelos professores ou pelas orientações administrativas e organizacionais do trabalho curricular que desenvolvem, quer seja pela sociedade e comunidade envolvente.

\subsection{Trabalho curricular da educação das expressões no ensino básico: avaliação de atividades}

Os inquiridos tecem posições pouco claras $(\chi=4,25$; $d p=1,81)$ sobre a avaliação das expressões seguir os mesmos procedimentos das restantes áreas programáticas. Os professores discordam $(\chi=3,84 ; \mathrm{dp}=2,05)$ que a avaliação das atividades de expressão seja somente formativa. Estes itens foram, também, aqueles em que se notaram valores de dispersão elevados. Em relação à avaliação das expressões possuir instrumentos específicos de recolha de informações, o conjunto dos professores não evidencia uma tendência clara $(\chi=$ $4,08 ; d p=1,73)$. Os inquiridos concordam $(\chi=5,20 ; d p=1,54)$ que a avaliação das expressões contribuiu para a avaliação global das aprendizagens dos alunos.

\section{DISCUSSÃO}

De acordo com os resultados do estudo, a educação das expressões é trabalhada como um espaço de interdisciplinaridade, o que não é prejudicial se não fosse, por um lado, uma desvalorização das expressões, e por outro se fosse verdadeiramente interdisciplinar e não apenas o recreio das áreas ditas nobres. Um segundo resultado é o empurrão das expressões para o tempo das AEC, que pode ser explicado, de novo, pela desvalorização das expressões e pela falta de preparação dos professores. Estamos perante um conjunto de fatores que poderá favorecer a exclusão da educação das expressões do currículo escolar real, pois o espaço curricular a que têm direito é preenchido com outras atividades. Segundo Tormenta (2015), pode ainda acontecer que esse tempo possa ser utilizado pelos docentes como momentos de descontração e de libertação da pressão das áreas curriculares que são avaliadas externamente. 
A inexistência de recursos físicos e materiais, identificada pelos professores como a maior fragilidade no desenvolvimento da educação das expressões, constitui uma extensão da controvérsia. Para estes professores do $1^{\circ}$ CEB faltam materiais; todavia, a produção de materiais é inerente à expressão que a própria educação das expressões deve potenciar. A expressão implica uma materialização, mesmo que corporal, envolta de processos de experimentação (BARRETT, 1979); um fraco saber dos professores sobre as propriedades dos materiais, ou das capacidades do movimento do corpo, leva a que seja atribuída tal responsabilidade aos técnicos das AEC. É considerado pelos professores inquiridos que estes especialistas trabalham melhor a educação das expressões; porém, para os professores do 1 Ciclo do Ensino Básico deverá importar mais a dimensão geral e pedagógica que integra a educação das expressões. É importante que os professores tenham conhecimentos sobre os valores pedagógicos da educação das expressões de forma a que não se desresponsabilizem desta área, tão importante para o desenvolvimento pessoal, cognitivo e social das crianças. Contudo, com a responsabilidade da educação das expressões delegada nos técnicos das AEC, não estarão a ser cumpridas as finalidades da LBSE, porque não estão garantidas as condições necessárias para que a educação das expressões seja incluída no currículo do $1^{0}$ CEB. A formação dos professores e intencionalidade no trabalho curricular das expressões deverão ser trabalhos a serem investigados por forma a se compreenderem os fenómenos então implícitos.

O planejamento das atividades é desenvolvido autonomamente pelos professores ou através da partilha pedagógica entre pares. Os professores que responderam ao questionário concordam que o departamento das expressões não interfere no planejamento das atividades, tendo sido revelado pelas professoras entrevistadas que os documentos de orientação do trabalho curricular têm um aproveitamento dúbio. Infere-se que a falta da articulação do agrupamento com as escolas do 1ํㅡㄹ, nomeadamente com a ausência de momentos de partilha pedagógica entre professores, possa ser um aspeto que leva a que, cada um na sua escola, trabalhe de per se no planejamento das tarefas.

Sobre a motivação das crianças para a dinamização das atividades, cabe ao docente definir quais são as estratégias que melhor se adequam às características da sua turma (PORTUGAL, 2004). Constatou-se, a partir da análise dos resultados, que a expressão e educação dramática e a expressão e educação musical são, maioritariamente, mobilizadas para 0 trabalho curricular da educação das expressões. As atividades maioritariamente desenvolvidas são: cantar canções; a improvisação de sons e atitudes; a recitação de textos; e a elaboração oral de uma história, enquadradas nas áreas organizativas de linguagem verbal e linguagem gestual. Com base nos resultados apresentados e nas interpretações acima presentes, pode-se considerar que essas são as atividades maioritariamente mobilizadas para o trabalho curricular, porque são de caráter promotor de aquisição de outras competências, tais como a oralidade e a escrita, essenciais para aprender a ler e escrever.

A prática educativa compreende, ainda, a avaliação das aprendizagens das crianças, necessária (NÓVOA, 1995), em respeito às atividades desenvolvidas no currículo. As avaliações das aprendizagens dos alunos são resultantes da avaliação diagnóstica (trata-se de fundamentar estratégias de diferenciação pedagógica), da avaliação formativa (permite a adoção de possíveis ajustes de estratégias e processos para o alcance do sucesso escolar do aluno) e a avaliação sumativa (avaliação global e final que se traduz numa classificação e 
certificação) (PACHECO, 2002). Os professores participantes do estudo têm posições pouco claras sobre a avaliação das expressões e a sua especificidade e/ou contribuição para a avaliação global das aprendizagens dos alunos. De novo fica a impressão de que o peso avaliativo das áreas de português e matemática impede uma atenção às potencialidades da avaliação das expressões.

\section{CONCLUSÕES}

A dicotomia do discurso dos professores de dar importância retórica à dinamização das expressões, mas depois de fazer pouco para as trabalhar é um assunto que, agora que se torna evidente, é necessário de ser investigado e refletido.

Apesar dos aspetos mais negativos salientados nos resultados, os professores identificam a importância da educação das expressões para o desenvolvimento global das crianças e trabalham em função do melhor que lhes podem dar. Esse sentimento da contribuição da atividade docente para o desenvolvimento da pessoa que é a criança ajuda a compreender os aspetos motivacionais que os docentes valorizaram e que lhes permitem (aos professores) um certo retorno de satisfação profissional (PEREIRA; MOURAZ, 2015).

O prazer de fazer aprender, associado ao fundamento da educação das expressões, é um aspeto valorizado como fator de motivação para o desempenho profissional, porém são vários os fatores implicados no trabalho curricular que impedem este contacto mais próximo com as expressões; mesmo assim, os professores identificam as mais-valias da educação das expressões no desenvolvimento das crianças enquanto cidadãs.

A identificação da educação das expressões como sendo uma libertação da criança, em que esta gesticula, manuseia, canta e ri é considerada pelos professores como um dos fatores da importância das expressões no trabalho curricular. Tal levanta algumas questões: se os professores têm consciência das mais-valias do corpo em movimento, por que não as mobilizam para o trabalho pedagógico? Será apenas pela escassez de recursos e de tempo, ou a busca pela resposta deve ir até à formação inicial e contínua que os professores realizaram? Sabe-se da grande influência da formação académica na estruturação da futura prática profissional dos professores, mas existirão desafios na área das expressões nas instituições de formação de professores que não se adequam à realidade vivida nas escolas?

Apesar da pouca experimentação do movimento do corpo, nas atividades educativas desenvolvidas - revelando mais um ponto fundamental para futuros estudos, que devam melhor compreender perceções de professores e alunos sobre o seu movimento expressivo do corpo - os professores reconhecem em todas as expressões capacidades e virtudes. As expressões centram-se na criança em movimento. É para auxiliar o seu crescimento e desenvolvimento que as diferentes expressões no programa do 1 EB têm princípios orientadores, que devem nortear toda a ação pedagógica. Em suma e do que ficou então explicitado, com a mobilização do quadro teórico e do trabalho empírico, tais princípios são: primado das experiências; primado da atividade; primado da comunicação; ligação entre técnica e expressividade/criatividade; articulação entre sentidos (órgãos sensoriais) e sentido; a experiência da Liberdade.

O enunciado desses princípios é também um "programa" pedagógico a cumprir em cada plano de turma, em cada aula de "expressões". Pode igualmente transformar-se no conjunto de critérios de avaliação das práticas curriculares dos docentes. 


\section{REFERÊNCIAS}

ARNHEIM, Rudolf. Consideraciones sobre la educación artística. Barcelona: Paidos, 1993.

BARBOSA, Ana Mãe. Arte/educação contemporânea: consonâncias internacionais. São Paulo:

Cortez, 2005.

BARDIN, Laurence. Análise de conteúdo. Lisboa: Edições 70, 2011.

BARRETT, Maurice. Art education. Lisboa: Editorial Presença, 1979.

COHEN, Louis; MANION, Lawrence; MORRISON, Keith. Research methods in education. New York: Routledge, 2007.

CONDESSA, Isabel. A atividade física curricular e extracurricular nas escolas do $1^{\circ}=$ ciclo de Ponta Delgada. In: OLIVEIRA, Beatriz; SIMÕES, Graça. Atividade Física, Saúde e Lazer. Lousã: Lidel, 2008. p. 347-358.

CRESWELL, John. Research design qualitative, quantitative and mixed methods approaches. Lincoln: SAGE, 2003.

EISNER, Elliot. Educating artistic vision. New York: Macmillan, 1972.

MALPIQUE, Manuela; LEITE, Elvira. Espaços de criatividade: a criança que fomos / a criança que somos... através da expressão plástica. Porto: Afrontamento, 1986.

NÓVOA, António. Vidas de professores. Porto: Porto Editora, 1995.

PACHECO, José Augusto. Critérios de avaliação na escola. In: ABRANTES, Paulo; ARAÚJO, Filomena. Avaliação das aprendizagens: das concepções às práticas. Lisboa: Departamento da Educação Básica, 2002. p. 53-64.

PACHECO, José Augusto. Currículo: teoria e praxis. Porto: Porto Editora, 1996.

PEREIRA, Fátima; MOURAZ, Ana. Crise da educação escolar e perceções dos professores sobre 0 seu trabalho: identidade professional e clima de escola em análise. Educação em Revista, v. 31, n. 1, p. 115-138, jan./mar. 2015.

PORTUGAL. MINISTÉRIO DA EDUCAÇÃO. Manual de organização curricular e programas do 1ำ ciclo. Lisboa, 2004.

READ, Herbert. Education through art. New York: Pantheon Books, 1943.

SANTOS, Arquimedes. Estudos de psicopedagogia e Arte. Lisboa: Livros Horizonte, 1999.

SANTOS, Arquimedes. Mediações artístico-pedagógicas. Lisboa: Livros Horizonte, 1989.

SOUSA, Alberto. Educação pela arte e artes na educação. Lisboa: Instituto Piaget, 2003. v.1.

SOUSA, Alberto. Educação pela arte e artes na educação. Lisboa: Instituto Piaget, 2003a. v.2.

SOUSA, Alberto. Educação pela arte e artes na educação. Lisboa: Instituto Piaget, 2003b. v.3. 
TORMENTA, Rafael. Expressões artísticas e educação básica: Oportunidades, capacidades e realidades. 2015. 400 f. Tese (Doutoramento) - Faculdade de Psicologia e de Ciências da Educação da Universidade do Porto, Porto, 2015.

\section{Apoio:}

Centro de Investigação e Intervenção Educativas da Faculdade de Psicologia e Ciências da Educação da Universidade do Porto, com a referência "PEst-OE/CED/UI0167/2014". 